\title{
Wind exposure as a factor influencing the littoral macrozoobenthic community: a methodological approach and preliminary findings
}

\author{
Aleksandra Bielczyńska \\ Department of Freshwater Protection, Institute of Environmental Protection - National Research Institute, Kolektorska 4, 01-692 Warsaw, \\ Poland, e-mail: a.bielczynska@ios.edu.pl
}

\begin{abstract}
The aim of the work was to analyze the influence of wave activity on invertebrate fauna living in the littoral zone. For this purpose, an algorithm was developed to analyze spatial and meteorological data, calculating the values of fetch and wind exposure. The taxonomic composition of the fauna and the values of selected water quality indicators were analyzed against the background of varied wind exposure, trophy, and various habitats. A significant negative impact of wind exposure on the taxonomic variety of the macrozoobenthic community, the number of Coenagrionidae damselflies and Baetidae mayflies was found. It is difficult to separate the impact of waves on the fauna from the impact of other natural and anthropogenic factors, because those factors may also be affected by water movements. The tool produced as part of this work can also be used to further investigate the issue of impact of waves on all the communities living in the littoral zone.
\end{abstract}

Key words: fetch, wind exposure, macrozoobenthos, ecological status

\section{Introduction}

Wave activity is one of the many factors affecting the littoral zone of lakes. It has both a direct and indirect influence on the community of aquatic invertebrates (Barton 1981). The intensity of waves has an impact on the kind and granularity of the substrate and the amount of suspended solids in water, and these factors affect the opportunities for development of water vegetation (Keddy 1982). The site's exposure to strong waves prevents sedimentation and thus contributes to the development of rocky substrate; moderate exposure contributes to the development of sandy substrate, and low, to the development of littoral vegetation (Tolonen et al. 2001). Thus, wave activity plays a part in the formation of habitats in the littoral zone, and by reducing the possibility of macrophyte development, it additionally limits littoral zone animals' access to shelter and food. Moreover, sediments may be suspended in water as a result of waving. Small particles floating in water may cause injury to some animals, i.e., clogging the gills or damaging the filtration apparatus (Bilotta and Brazier 2008; Jones et al. 2012). Resuspension of sediments as a result of waves and the resultant water turbidity are the main factors that affect the ecosystem of shallow lakes. Zoobenthos is also extremely important in shallow lakes because this group is responsible for a much higher proportion of secondary production than in deep lakes, creating a significant food base for fish. Therefore, the impact of wave activity on the ecosystem is especially important in shallow lakes (Sheffer 2001).

According to Pieczyńska (1990), isolated places with a silty bottom, well-developed vegetation and high availability of detritus are the habitat that helps develop a higher abundance and diversity of invertebrate fauna. A low diversity of invertebrate fauna usually reflects a worsened condition of the community, which results in poor ecological status (Poikane et al. 2016), although it may be associated with natural properties of the habitat, e.g., high exposure to waves.

Full comprehension of the impact of wave activity on benthic fauna is significant from the perspective of evaluation of the quality of water in accordance with the Water Framework Directive (EC 2000). Macrozoobenthos is one of communities of organisms used as an indicator of the ecological status of surface waters. Eutrophication pressure may be a factor with a similar force of influence on the macrozoobenthic community as natural waves, especially in shallow lakes (Cai et al. 2016). Changes in the structure of macrozoobenthos connected with natural waves may overlap with changes connected with anthropogenic pressure and thus make 
the reliable assessment of the ecological status difficult (Brauns et al. 2007).

Natural waves are the product of atmospheric conditions (the force, direction and duration of wind blowing) and the formation of the lake basin. Two indices are commonly used in source literature: fetch, i.e., the mean distance over which wind can blow above the water table, and wind exposure, being the product of the fetch and meteorological conditions (Keddy 1982; Brodersen 1995). To calculate the fetch, transformations and geometric measurements are needed, which are hard and time-consuming if done manually. The Geographic Information System (GIS), which is an instrument used to construct models of geographical objects and perform complex analyses on the models, makes this task much easier. It can be used in many areas of science, i.a., in limnology. It is much easier to apply than the analog methods of limnological analyses (Urbański and Kryla-Straszewska 2010; Jażdżewska and Urbański 2013). The aim of this work was to create a GIS tool that could be used in determining the wind exposure of a site. The tool can be applied in ecological research concerning various communities of organisms living in the littoral zone, not only invertebrate fauna. The tool was developed and tested using data from 11 lakes from north-eastern Poland. It was used to analyze the influence of wind exposure on invertebrate fauna in the littoral zone of lakes with varied trophy.

\section{Data sources}

\section{Meteorological and geometric data for the model}

Archival meteorological data from the Institute of Meteorology and Water Management - National Research Institute (danepubliczne.imgw.pl) concerning the direction and force of wind, coming from five selected climatological stations located closest to the in- vestigated sites (Suwałki, Kętrzyn, Olsztyn, Mikołajki, Mława) was used in the work. The distance between the investigated site and the center from which the related meteorological data was obtained was between 1.5 and $35 \mathrm{~km}$. Both the direction and the speed of wind were measured every hour. Since daily data were necessary for the model, the measurements were averaged within days, with consideration of separate principles of averaging directions (Mardia and Jupp 2000). Data from the year preceding the collection of the fauna sample was included in the analyses.

The geometry of lakes for analyses was taken from the vector polygon layer of the Hydrographic Map of Poland in the scale 1:50,000 (MPHP50) obtained from the National Water Management Holding 'Polish Waters'.

\section{Biological and physico-chemical data for testing}

Data concerning littoral invertebrate fauna comes from the author's own research (Bielczyńska 2018). In the years 2016-2017, samples of invertebrate fauna were taken from the littoral zone of 11 lakes representing the trophic gradient (Fig. 1, Table 1). These were highly alkaline, stratified lakes with a varied impact of the catchment on the lake. Each sample was taken using a 0.5 $\mathrm{mm}$ net with the kick sampling technique. At each site, a separate sample was taken from the sandy substrate, from the substrate covered with emerged macrophytes, and an integrated sample from all the habitats present at the research site, proportionally to their share. There was no integrated sample from Lake Ryńskie, so that lake was not included in some of the statistical analyses. The samples were fixed with ethanol. The animals were identified up to the family level. Based on determinations using the ASTERICS 4.04 program (Wageningen Software Labs), a number of metrics were also calculated to assess the ecological status of waters. These were

Table 1. Values of basic morphological and physico-chemical parameters of the studied lakes

\begin{tabular}{|l|r|r|c|c|c|c|c|c|c|c|c|}
\hline \multicolumn{1}{|c|}{ Lake } & Area & Depth & Year & CHL-a & SD & O2 & COND & pH & TN & TP & Trophic state \\
\hline Kruklin & 356 & 4.9 & 2017 & 32.1 & 1.1 & 0.0 & 421 & 8.3 & 1.72 & 0.052 & eutrophic \\
\hline Skanda & 51 & 5.8 & 2017 & 32.0 & 1.0 & 0.1 & 382 & 8.0 & 2.03 & 0.050 & eutrophic \\
\hline Jegocin & 127 & 9.0 & 2016 & 4.3 & 4.7 & 5.0 & 161 & 8.3 & 0.69 & 0.018 & mesotrophic \\
\hline Kownackie & 216 & 9.4 & 2017 & 3.8 & 3.5 & 0.2 & 220 & 8.2 & 0.89 & 0.040 & mesotrophic \\
\hline Wukśniki & 117 & 23.4 & 2017 & 5.1 & 3.2 & 49.4 & 275 & 8.3 & 0.67 & 0.038 & mesotrophic \\
\hline Ryńskie & 661 & 11.0 & 2016 & 31.3 & 1.1 & 0.1 & 273 & 8.5 & 0.97 & 0.058 & eutrophic \\
\hline Kortowskie & 90 & 6.4 & 2016 & 18.2 & 1.3 & 3.0 & 378 & 8.2 & 1.32 & 0.115 & eutrophic \\
\hline Mikołajskie & 498 & 11.2 & 2016 & 27.5 & 1.2 & 0.1 & 249 & 8.4 & 0.89 & 0.047 & eutrophic \\
\hline Olecko Małe & 221 & 10.3 & 2017 & 17.6 & 1.6 & 0.0 & 419 & 8.2 & 2.23 & 0.063 & eutrophic \\
\hline Roś & 1888 & 8.1 & 2016 & 16.5 & 1.6 & 0.1 & 273 & 8.2 & 1.06 & 0.041 & eutrophic \\
\hline Mokre & 841 & 12.7 & 2017 & 18.6 & 1.6 & 0.0 & 291 & 8.3 & 0.87 & 0.038 & eutrophic \\
\hline
\end{tabular}

Area - lake surface area (ha), Depth - mean lake depth (m), Year - year of research, CHL- $a$ - chlorophyll- $a$ concentration $\left(\mu \mathrm{g} \mathrm{dm}{ }^{-3}\right)$, SD - Secchi disk depth (m), O2 - hypolimnion oxygen saturation (\%), COND - conductivity $\left(\mu \mathrm{S} \mathrm{cm}^{-1}\right), \mathrm{pH}$ - reaction, TN - total nitrogen $\left(\mathrm{mg} \mathrm{N} \mathrm{dm}{ }^{-3}\right)$, TP - total phosphorus $(\mathrm{mg}$ $\left.\mathrm{P} \mathrm{dm}^{-3}\right)$. Trophic state according to Kajak (2001) 


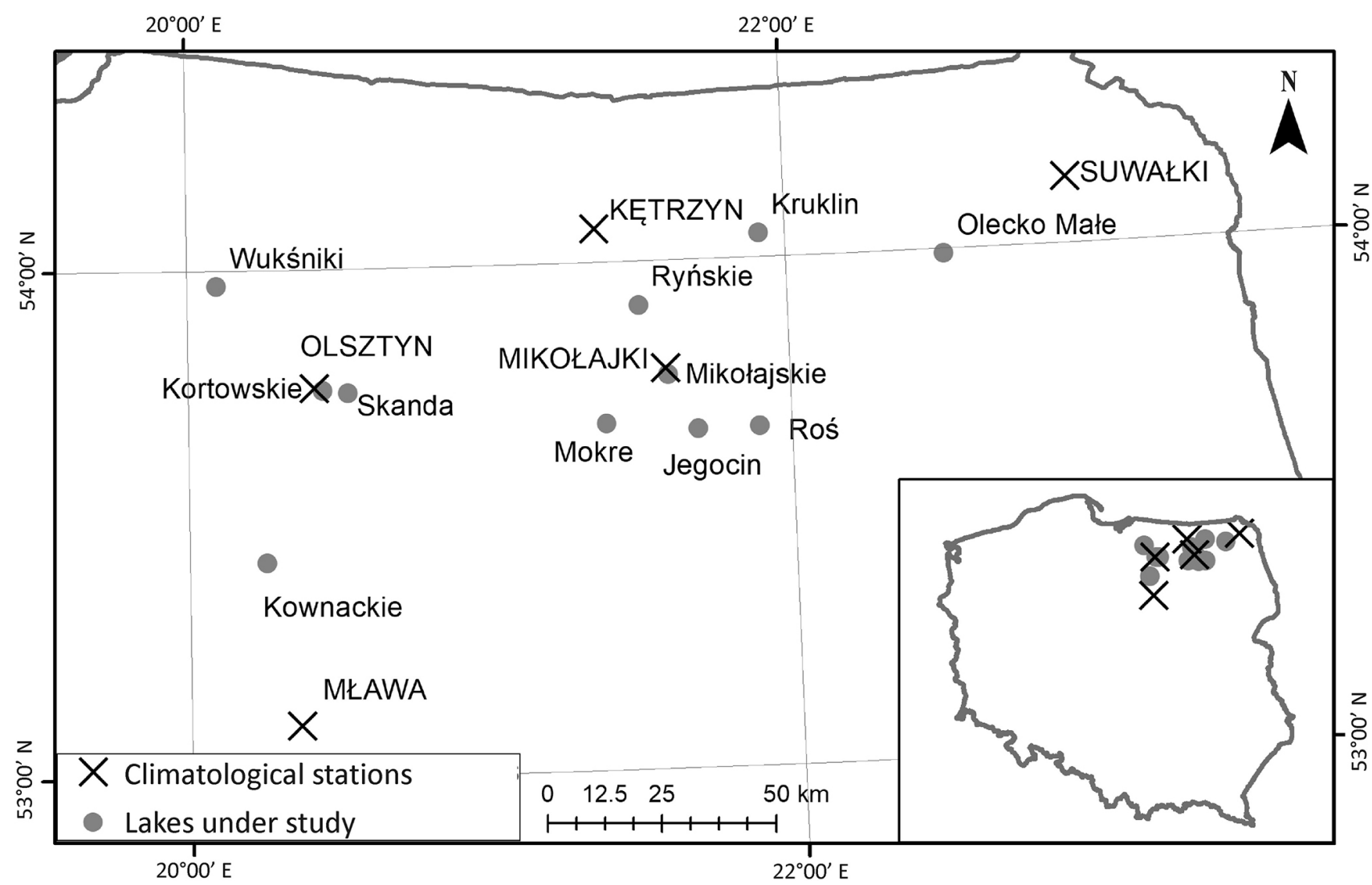

Fig. 1. Location map of the investigated lakes and nearby climatological stations

the indicators that describe taxonomic diversity, the taxonomic composition of the fauna and the presence of taxa tolerant and sensitive to pollutants. 29 metrics were calculated for the analyses.

\section{Methods}

In order to determine the intensity of wave activity at the research site, two parameters were chosen: fetch and wind exposure, in accordance with the approach proposed by Brodersen (1995). The fetch is calculated by plotting five lines running radially from the research site to the lake shore, where the middle line connects the site with the opposite shore and the remaining four lines are plotted at the angles of $22.5^{\circ}$ and $45^{\circ}$, two on each side, so that the whole angle made by the extreme lines is $90^{\circ}$. Then, the weighted average of the length of those lines is calculated, with the weight for a line being the cosine of the angle it makes with the middle line. The site's relative exposure to the wind is described with the formula (Brodersen 1995):

$$
E=\log _{10}\left(1+f w h d^{-2}\right)
$$

where: $f$ - fetch $(\mathrm{km}), w$ - ratio of number of days in a year when the wind blows towards the site to the total number of days in a year; $h$ - mean wind speed $\left(\mathrm{m} \mathrm{s}^{-1}\right)$; $\mathrm{d}-\operatorname{depth}(\mathrm{m})$.

\section{Models}

In order to obtain the algorithm for spatial analyses, two complex models were prepared in the ArcGIS Pro 2.2.0 software (Esri), using the Model Builder program. The models were called Fetch and Exposure. In the models a number of functions were used to geoprocess vector data and calculations. Scripts in Python were also used.

The Fetch model was used to do geometric transformations and calculate the mean fetch. The input parameters for this model were: the polygon layer with the lake, and the point layer with the site (it must be located on the lake contour, i.e., on the edge or a vertex of its shape), and the table template used to calculate the angles at which the lines to the opposite shore are plotted. The algorithm involved two cases: a site located on a section, and a site located on a vertex. The conditional construct included alternative algorithms for both cases. In the former case, the model plots the middle line at the right angle to the section on which the site is located, and in the latter case, it averages the directions of the two sections adjacent to the vertex using the Linear Directional Mean (LDM) tool and thus obtains the referential direction to plot the middle line at the right angle (Fig. 2). 


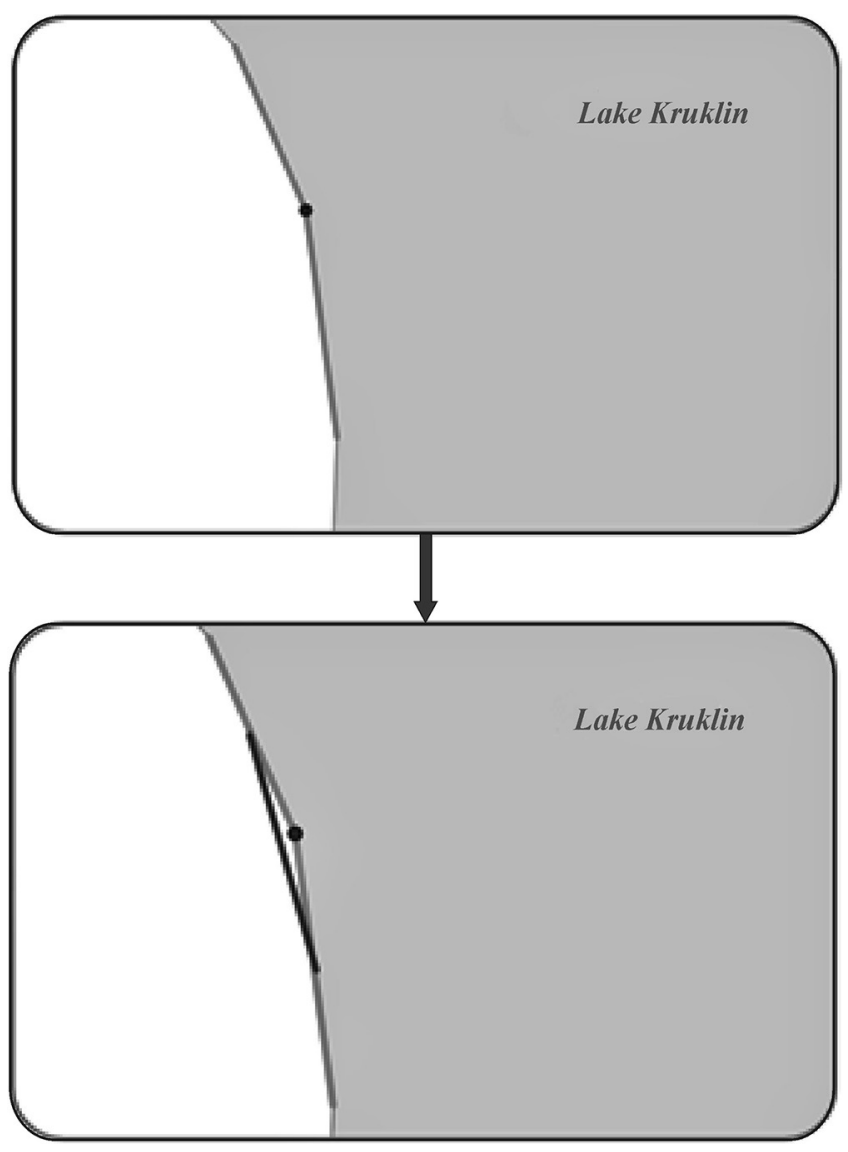

Fig. 2. Illustration of how the Linear Directional Mean works in the Fetch model in the case of a research site located on a vertex Light grey field - the lake, grey line - a fragment of the shore, black line - the averaged direction, black dot - the research site.

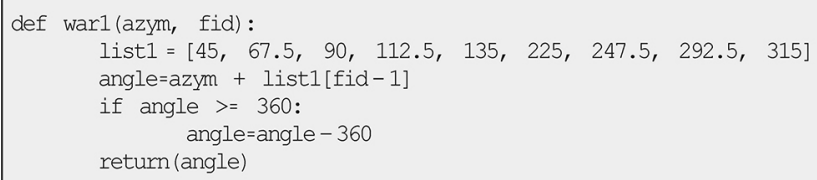

Fig. 3. The Python function used to calculate the azimuths of auxiliary lines to obtain the fetch

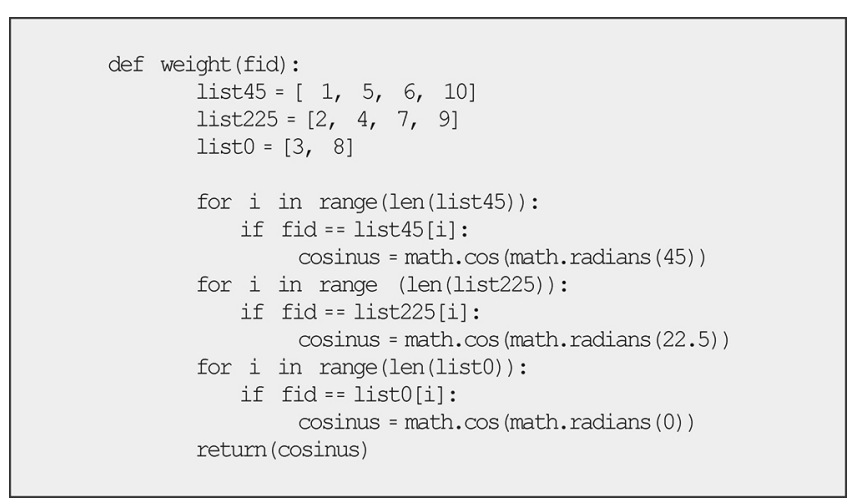

Fig. 4. The Python function used to calculate the weights of auxiliary lines to obtain the fetch
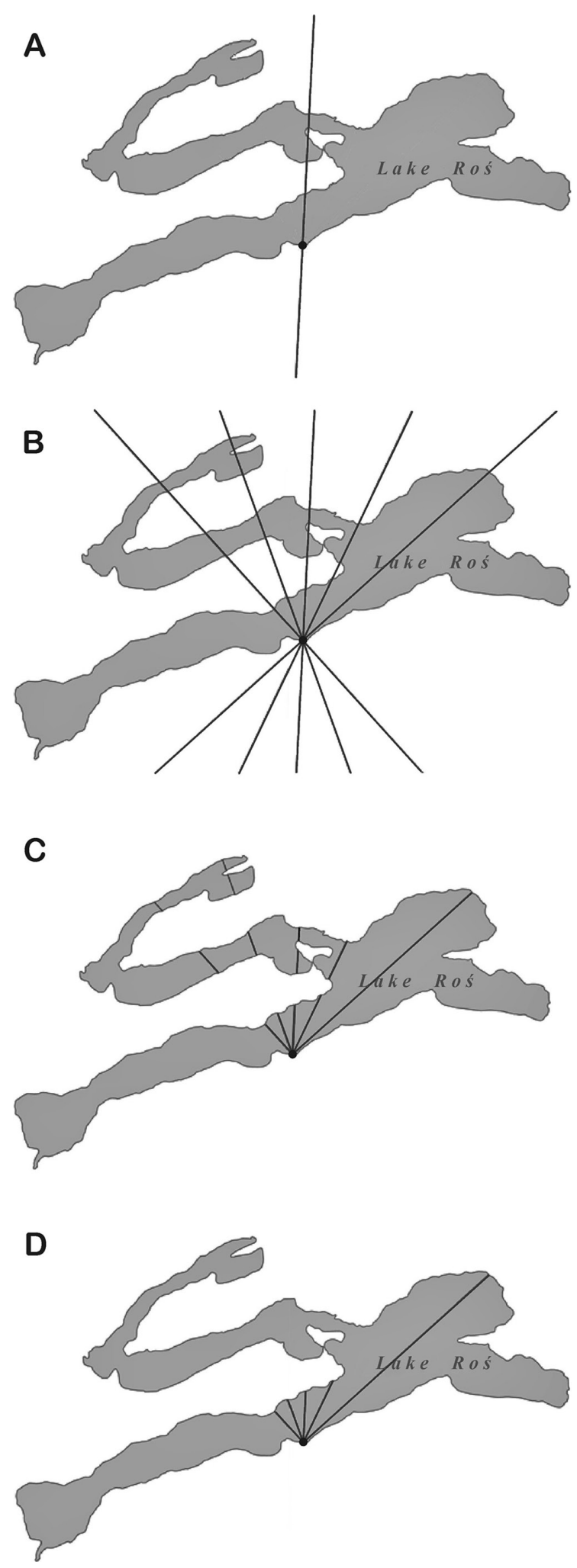

Fig. 5. The subsequent stages of the algorithm in the Fetch model used to plot lines to calculate the fetch

$\mathrm{A}$ - plotting the middle line (perpendicular to the shoreline at the place of the research site), B - plotting the auxiliary lines, $\mathrm{C}$ - clipping the lines to the lake contour, D - removing the extra fragments of the lines (not tied to the research site). 
The auxiliary lines to calculate the fetch were plotted with reference to the rectangular line, cutting it through every $22.5^{\circ}$ at the point of the research site. A script in Python was used to calculate the azimuths of the plotted lines (Fig. 3). In the same way, the lines were given attributes being the cosine of the angle between the auxiliary line and the middle line (Fig. 4). These values were later used as weights attributed to the lengths of the lines in the formula for the fetch.

Using the Bearing Distance to Line tool, lines with the previously calculated azimuths were plotted (Fig. 5B). They were then geoprocessed by clipping to the polygon of the lake (Fig. 5C) and only the fragments were selected which were adjacent to the research site (Fig. 5D). The outcome of the model is the linear layer and a table with the calculated fetch.

The Exposure model used the results of the Fetch model and the table with meteorological data. Another parameter of the model was the variable of the sampling depth. This model selected days when the direction of wind was opposite to the range of directions identified by the extreme lines. The selection was preceded by a conditional construct taking into consideration two possibilities, i.e., the $0^{\circ}$ direction could be between $90^{\circ}$ of the range of wind directions, then the selection instruction included all the values higher than the first angle or lower than the second angle. If the $0^{\circ}$ direction was beyond the range of the sought values, the algorithm of selection chose all the values higher than the first angle and lower than the second angle (Fig. 6).

The model then calculated the days with the selected direction of wind and averaged its speed. The last step

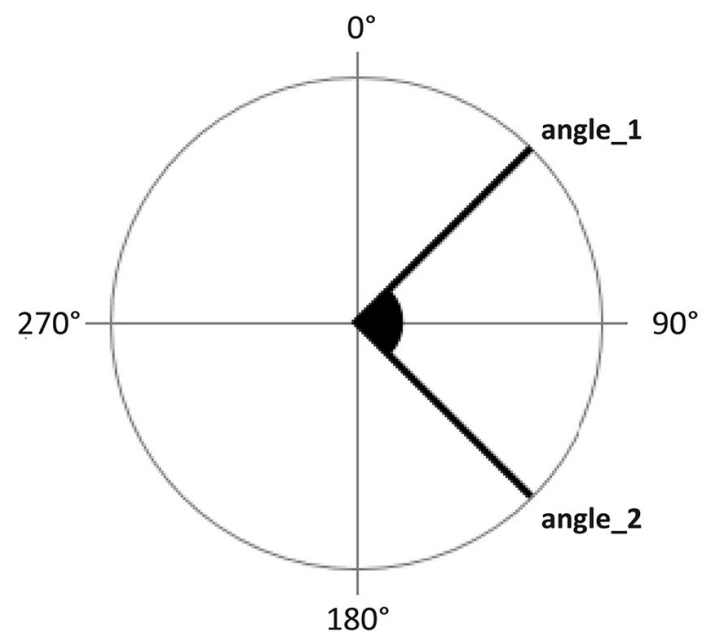

exposure $=$

math. $\log \left(\left(1+\left(\%\right.\right.\right.$ fetch $\%$ * !windy_days! * !MEAN_speed_W! * $\left.\left.\left.(\% \text { depth } \%)^{\star \star}(-2)\right)\right), 10\right)$

Fig. 7. The formula included in the Calculate Field tool used to calculate the wind exposure in the Exposure model

was the calculation of wind exposure (Fig. 7). The output of the model is a table with the proportion of days when wind blows towards the site, the mean speed, and the calculated wind exposure.

\section{Statistical analyses}

The obtained values of mean fetch and wind exposure with the basic data concerning the physico-chemical properties of the waters were analyzed in terms of the influence on invertebrate fauna. Based on the integrated samples (fauna from all the habitats present at the research site), linear regression analyses were performed, preceded by the verification whether the studied variables represent the normal distribution using the Shapiro-Wilk test. The analyses were performed using the STATISTICA 12 program (StatSoft Inc. 2014). In order to analyze the influence of environmental variables on the taxonomic composition of the macrozoobenthic community in the substrate-specific way, redundancy analysis (RDA) was carried out using the CANOCO 4.5 program (ter Braak and Šmilauer 2002). Redundancy analysis was carried out for samples from sandy substrate and substrate with emerged macrophytes separately.

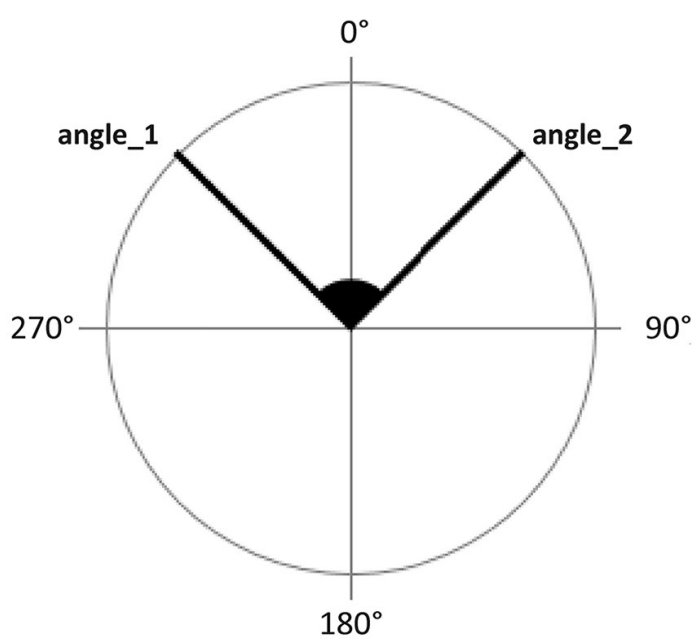

direction_W is Greater Than or Equal to angle_1

And direction_W is Less Than or Equal to angle_2
direction_W is Greater Than or Equal to angle_1

Or direction_W is Less Than or Equal to angle_2

Fig. 6. Two variants of the selection of wind direction values. Angle_1, angle_2 denote the extreme values of the selected range 

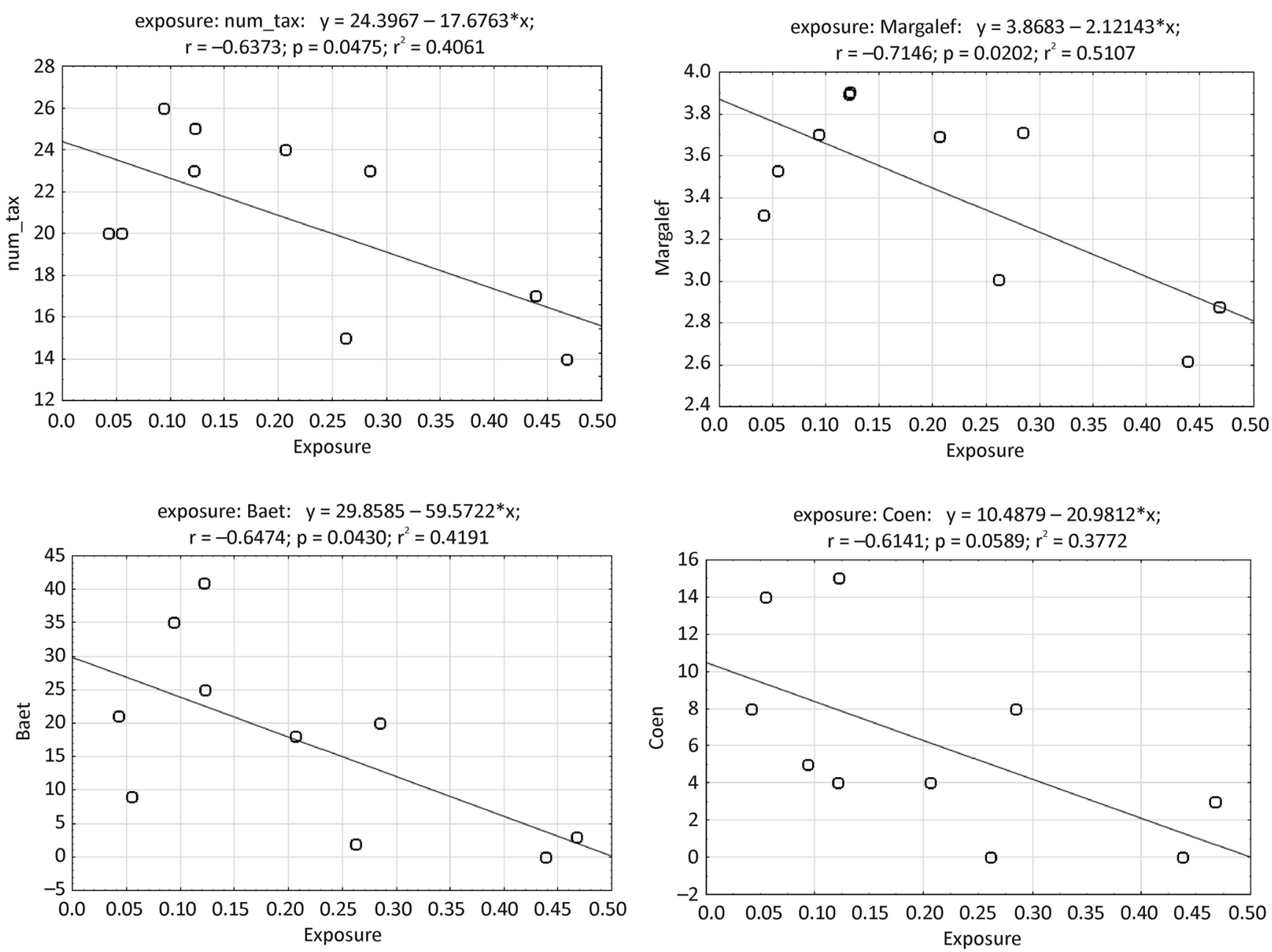

exposure: Crust\%: $y=1.4571+27.8189 * x$

$r=0.7560 ; p=0.0114 ; r^{2}=0.5716$

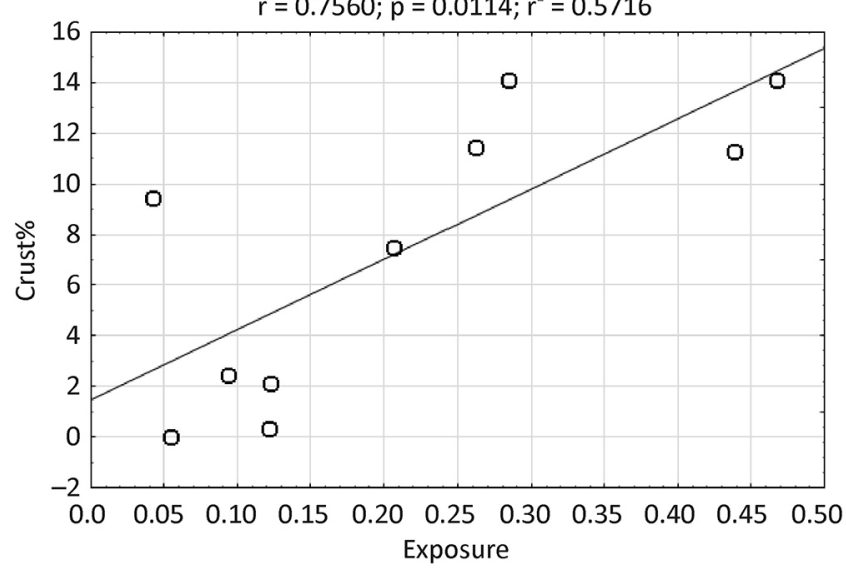

Fig. 8. Diagrams of linear regressions showing relationships of selected taxonomic groups and selected indicators of biodiversity on wind exposure

Denotations: num_tax - the number of taxa, Margalef - Margalef's richness index, Baet - the number of Baetidae, Coen - the number of Cenagrionidae, Crust\% - the proportion of Crustacea. 


\section{Results}

\section{Fetch and exposure}

The range of fetch of the investigated lakes was between $0.07 \mathrm{~km}$ (Lake Kruklin) to $1.69 \mathrm{~km}$ (Lake Roś), and wind exposure had values between 0.04 (Lake Kruklin) to 0.47 (Lake Mokre) (Table 2).

Table 2. Results of the fetch (in $\mathrm{km}$ ) and wind exposure (dimensionless) calculations obtained for the lakes under study

\begin{tabular}{|l|c|c|}
\hline \multicolumn{1}{|c|}{ Lake } & Fetch & Wind exposure \\
\hline Kruklin & 0.07 & 0.04 \\
\hline Skanda & 0.21 & 0.05 \\
\hline Jegocin & 0.33 & 0.09 \\
\hline Kownackie & 0.65 & 0.12 \\
\hline Wukśniki & 0.86 & 0.12 \\
\hline Ryńskie & 0.83 & 0.20 \\
\hline Kortowskie & 0.48 & 0.21 \\
\hline Mikołajskie & 0.58 & 0.26 \\
\hline Olecko Małe & 0.58 & 0.28 \\
\hline Roś & 1.69 & 0.44 \\
\hline Mokre & 1.30 & 0.47 \\
\hline
\end{tabular}

The fetch and exposure indicators are strongly correlated (Pearson's correlation coefficient $\mathrm{r}=0.86$ at $\mathrm{p}=$ 0.0016). Therefore, in further analyses only one of them was used as an environmental variable describing natural wave activity. Since exposure takes into consideration not only landform features but also meteorological conditions, it was regarded as the more reliable indicator and included in the analyses as the environmental factor affecting invertebrate fauna.

\section{Relationships between environmental variables and the taxonomic composition of invertebrate fauna}

Out of 51 taxa identified in the samples from integrated samples from 10 lakes, only 5 displayed the normal distribution on the basis of the Shapiro-Wilk test (Asellidae, Baetidae, Coenagrionidae, Lymneaidae, Leptoceridae). Out of the 29 investigated metrics, 24 represented normal distribution. These indicators were analyzed in terms of the impact of exposure on their values. In the case of Baetidae mayflies and Coenagrionidae damselflies, a statistically significant decrease in the number of individuals with increasing wind exposure was observed. Similarly, a decrease in biodiversity expressed in the number of taxa and the Margalef's index (Margalef 1958) was observed with growing exposure. The proportion of crustaceans (Crustacea) in the total fauna was directly proportional to the exposure rate (Fig. 8).
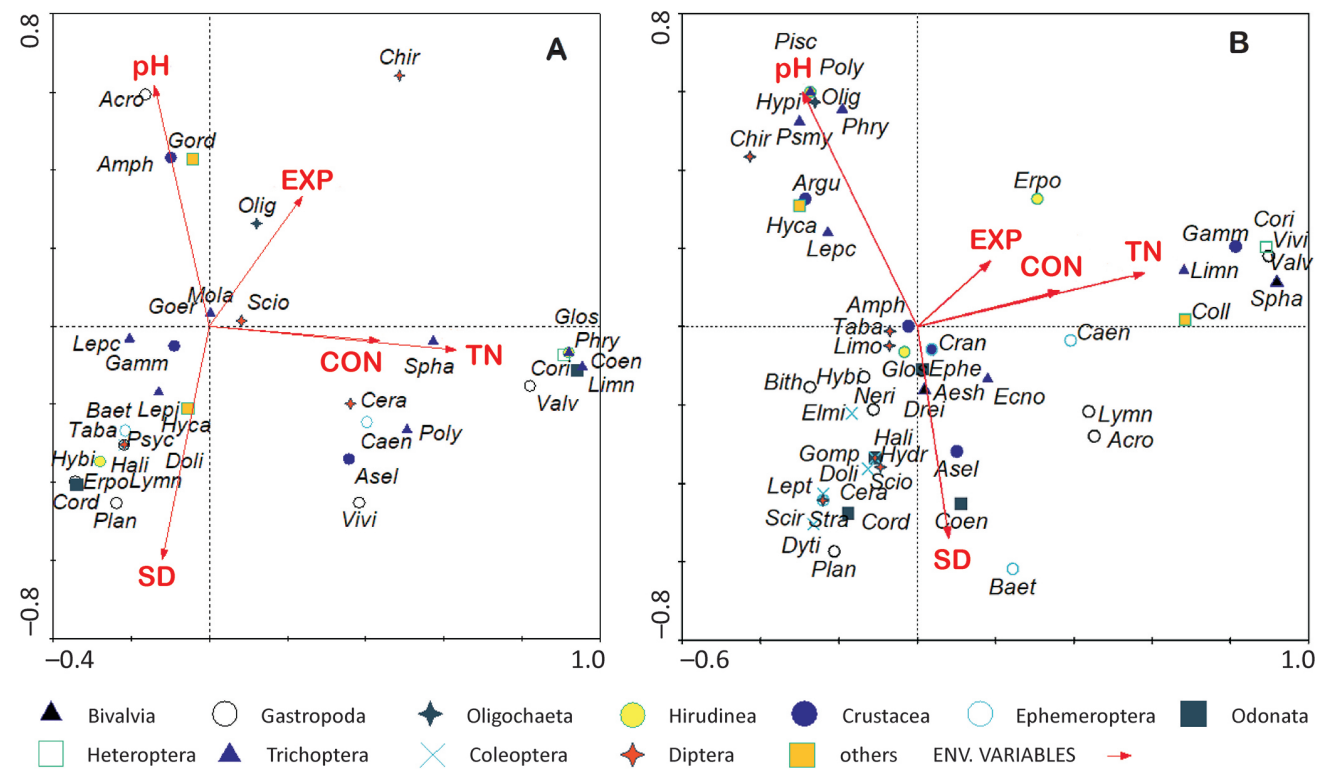

Fig. 9. Redundancy analysis (RDA) with division into habitats

A - sandy substrate (eigenvalues: axis $1-0.594$, axis 2 - 0.073, sum of eigenvalues of canonical axes: 0.728 ), B - substrate covered with emerged macrophytes (eigenvalues: axis $1-0.382$, axis $2-0.138$, sum of eigenvalues of canonical axes: 0.623 ).

Unprocessed data: $\mathrm{pH}$ - water reaction, EXP - wind exposure, COND - conductivity, TN - total nitrogen, SD - Secchi disk depth.

Abbreviations of taxa names: Acro - Acroloxidae, Aesh - Aeshnidae, Amph - Amphipoda, Argu - Argulidae, Asel - Asellidae, Baet - Baetidae, Bith - Bithyniidae, Caen - Caenidae, Cera - Ceratopogonidae, Chir - Chironomidae, Coen - Coenagrionidae, Coll - Collembola, Cord - Corduliidae, Cori - Corixidae, Cran - Crangonyctidae, Doli - Dolichopodidae, Drei - Dreissenidae, Dyti - Dytiscidae, Ecno - Ecnomidae, Elmi - Elmidae, Ephe - Ephemeridae, Erpo - Erpobdellidae, Gamm - Gammaridae, Glos - Glossiphonidae, Goer - Goeridae, Gomp - Gomphidae, Gord - Gordiidae, Hali - Haliplidae, Hybi - Hydrobiidae, Hyca - Hydrachnida, Hydr - Hydrophilidae, Hypi - Hydroptilidae, Lepc - Leptoceridae, Lepi - Lepidostomatidae, Lept - Leptophlebiidae, Limn Limnephilidae, Limo - Limoniidae, Lymn - Lymnaeidae, Mola - Molannidae, Neri - Neritidae, Olig - Oligochaeta, Phry - Phryganeidae, Pisc - Piscicolidae, Plan - Planorbidae, Poly - Polycentropodidae, Psmy - Psychomyidae, Psyc - Psychodidae, Scio - Sciomyzidae, Scir - Scirtidae, Spha - Sphaeriidae, Stra - Stratiomyidae, Taba - Tabanidae, Valv - Valvatidae, Vivi - Viviparidae. 
The DCA showed a gradient length of 2.249 standard deviations, which determined the choice of direct use of RDA (redundancy analysis). Samples from different habitats, from sandy substrate (Fig. 9A) and from emerged macrophytes (Fig. 9B) were considered separately. In the space of ordination diagram most zoobenthic taxa clustered on the opposite side of the vector representing exposure. For samples with sandy substrate the total explained variance was higher than for samples with macrophyte substrate, and the vector of the influence of exposure was longer, which confirms the stronger influence of that factor on the macrozoobenthic community. In the ordination space, few taxa displayed a correlation with the vector of exposure, which proves that macrozoobenthic species do not prefer water movements caused by waves. On the diagram presenting sandy substrate, Chironomidae and Oligochaeta are the closest.

\section{Discussion}

Fetch in inland waters may reach values higher than the range mentioned here, e.g., in the great American lakes it may exceed $100 \mathrm{~km}$ (Mason et al. 2018). In small lakes (below $10 \mathrm{ha}$ ) the influence of waves caused by wind on the littoral zone is regarded as negligible (Strayer and Findlay 2010). However, even in small lakes with low fetch, the influence of waves on the content of organic matter and hydration of sediments can be observed, so even a fetch smaller than $1 \mathrm{~km}$ may potentially affect the habitat of benthic fauna (Cyr 1998). Against the background of these reports, the gradient of fetch $(0.07-1.69 \mathrm{~km})$ and wind exposure $(0.04-$ 0.47 ) obtained in this study proved to be moderate.

Regression analyses showed that greater exposure of the site to wind contributes to reducing the number of taxa and the biodiversity of the community (Fig. 8). The outcomes of redundancy analysis show that sites subject to intensive waving are not an optimum habitat for the development of macrozoobenthos, and the fauna is poorer in places exposed to waves (Fig. 9). The Water Framework Directive (EC 2000) formulates guidelines concerning the criteria of assessment of invertebrate fauna in lakes. One criterion is the diversity of taxa of invertebrates. Pursuant to this guideline, European Union Member States have included metrics of diversity in the assessment of water quality (Poikane et al. 2016). However, the diversity of the macrozoobenthic community may be reduced by the natural factor of wind exposure, which makes this element difficult to apply in the assessment of ecological status. Koperski (2011) points out that the general diversity of macrozoobenthos is a poor indicator of water quality, i.a., because it is affected by many taxon-specific factors, and the general diversity is their product. In this study, varied influence of wind exposure on different groups of invertebrates was also observed. Baetidae mayflies and Coenagrionidae damselflies, i.e., two numerous and common families of insects, proved to be sensitive to wind exposure; their number was significantly lower at sites with high exposure. A reverse relationship was observed in the case of the matrix of the proportion of crustaceans in the total number of fauna (Fig. 8). In the study of lake Huron, a negative correlation was shown between the fetch and the occurrence of crustaceans (Cooper et al. 2014). Similarly, Burton et al. (2004) observed that Gammarus (Gammaridae), Crangonyx (Crangonyxidae) and Caecidotea (Asellidae) prefer places sheltered from wind. It must be emphasized, however, that those studies refer to American Great Lakes and so the scale of the lake size and the range of fetch on those objects is incomparably greater than in the case of lakes in Poland. In conditions of moderate diversity of wind exposure crustaceans proved to be more resistant to wave activity than other groups of benthic invertebrates.

The aim of the RDA was to show the potential diversity in the influence of exposure of the site on the fauna depending on the habitat. Sandy substrate and emerged macrophytes were analyzed separately. Due to their structure, macrophytes provide shelter for the fauna and compensate for the influence of water movements on invertebrate fauna (Tolonen et al. 2001). However, the findings obtained by Brauns et al. (2007) show the opposite relationship. In studies of German lakes, fauna inhabiting reed proved to be more related to wind exposure than fauna inhabiting sandy substrates. The density of reed stems was negatively correlated with the degree of wind exposure. Fauna from the sandy substrate displayed the strongest relation with total phosphorus content in water. The findings of this study show that the influence of exposure on fauna from sandy substrate is greater than on fauna from substrate covered with emerged macrophytes (Fig. 9). It is likely that in the case of samples from the reed bed, fauna is also influenced by other factors not included in the study (e.g., the species composition of vegetation or the availability of food base). It seems that the fauna in the reed bed is sheltered, which in a way lowers the impact of exposure. A similar impact was observed not only for vascular plants but also for filamentous algae (Brodersen 1995; Ratti and Barton 2003). According to Gabel et al. (2008), the more complex the structure of the material, the better the animals are protected from washing out. On the basis of the experiment, the researchers ranked substrates from the least to the most resistant to washing animals out: sand, coarse woody debris, rocks, reed, and tree roots.

The very movement of water caused by waves also has an influence on the development of macrophytes: 
direct, by transporting seeds, uprooting or damaging single individuals, and indirect, by erosion, transporting and depositing sediments, nutrients and organic matter (Keddy 1982). On unstable substrate, where the lake shore is eroded, macrophytes do not have good conditions for development. Because they also create a habitat for invertebrate fauna, it indirectly contributes to the impoverishment of the fauna (James et al. 1998).

In the RDA, the Chironomidae and Oligochaeta were located close to the vector of exposure in the ordination space, although their position may have been caused by the location in the trophy gradient expressed by the SD vector (Fig. 9). These taxa are also common and resistant to high trophy (Armitage et al. 1995; Krodkiewska and Michalik-Kucharz 2009). According to Cooper et al. (2014), exploring the degraded Saginaw Bay in lake Huron, Oligochatea display a preference for exposed sites. On the other hand, in a study by Weatherhead and James (2001), Chironomidae and Oligochaeta displayed the opposite preference - for sites with low wind exposure, although the area of their study was oligo- and mesotrophic great lakes in New Zealand.

The separation of individual factors affecting the invertebrate fauna is difficult because these factors are often interrelated. Weatherhead and James (2001) created a hierarchy of factors that influence invertebrate fauna. According to them, the most important are: the type of the substrate, the biomass of macrophytes and the presence of detritus. Less important are: the depth of the site, exposure to waves, water transparency, and water level fluctuations. However, given that the factors from the second group have an influence on the factors from the first one (e.g., changes in the level of water affect the biomass of macrophytes, and exposure to wind affects the biomass of detritus), we can see how complex is the littoral zone of lakes. Cai et al. (2016), exploring a big, degraded lake in China, separated statistically between the influence of eutrophication and of wave activity on the fauna using the Variation Partitioning method. They showed that the influence of wave activity is as strong as the influence of eutrophication, and often this influence is the opposite (inhibiting intense sedimentation caused by eutrophication).

The results show that waving caused by wind is a factor which may affect both the taxonomic composition and the diversity of a macrozoobenthic community. This influence may potentially disturb the assessment of the ecological status of water based on benthic invertebrates. Therefore, the influence of waving on invertebrate fauna needs to be explored further and taken into consideration when selecting metrics for the assessment of water quality and choosing the location for the sampling of macrozoobenthos for bioindicator purposes.
The results obtained after the use of the model in the preliminary group of investigated lakes show that the influence of natural wave activity on invertebrate macrofauna is difficult to assess against the background of other environmental factors. The developed tool for the determination of fetch and wind exposure may potentially be used in the analysis of a larger pool of data. The tool can also be used in analyses concerning other groups of organisms living in the littoral zone, e.g., to determine the influence of wave activity on macrophytes (Chambers 1987; Rea et al. 1998; Cheruvelil and Soranno 2008) or epiphytic algae (Cattaneo 1990). The findings of further studies using the model are especially interesting from the perspective of climate changes. Climatic models forecast the increase in the mean annual wind speed (Eichelberger et al. 2008), as well as the occurrence of strong gusts (Cheng et al. 2014), as a result of which it is even more significant to recognize the consequences of these changes for aquatic organisms.

\section{Acknowledgements}

The Hydrographic Map of Poland in the scale 1:50,000 (MPHP50) obtained from the National Water Management Holding 'Polish Waters' and meteorological data obtained from the Institute of Meteorology and Water Management - National Research Institute were used in the work.

Data collected within the statutory activity of the Institute of Environmental Protection - National Research Institute financed with subsidies from the Ministry of Science and Higher Education (subj. no. 10-OMBJ-1509/16 and 10-OM-BJ-1541/17) were also used. Inspection for Environmental Protection provided data obtained within the framework of state environmental monitoring.

I would like to thank dr hab. Jacek Urbański, prof. of Gdańsk University for help and advice in developing models in ArcGIS.

\section{References}

Armitage P.D., Pinder L.C., Cranston P. (eds.), 1995, The Chironomidae: biology and ecology of non-biting midges, Chapman and Hall, London, 588 pp.

Barton D.R., 1981, Effects of Hydrodynamics on the Distribution of Lake Benthos, [in:] Lock M.A., Williams D.D. (eds), Perspectives in running water ecology, Springer, Boston: 251-263.

Bilotta G.S., Brazier R.E., 2008, Understanding the influence of suspended solids on water quality and aquatic biota, Water Res. 42(12): 2849-2861.

Bielczyńska A., 2018, Wartość bioindykacyjna zespołów makrofauny bentosowej z różnych typów siedlisk w litoralu jezior, Etap II (Bioindicative value of lakes' benthic 
fauna from various habitats, Part II) [typescript], IOŚPIB, Warszawa, 27 pp (in Polish).

Brauns M., Garcia X.F., Pusch M.T., Walz N., 2007, Eulittoral macroinvertebrate communities of lowland lakes: discrimination among trophic states, Freshwater Biol. 52(6): 1022-1032.

Brodersen K.P., 1995, The effect of wind exposure and filamentous algae on the distribution of surf zone macroinvertebrates in Lake Esrom, Denmark, Hydrobiologia 297: 131-148.

Burton T.M., Uzarski D.G., Genet J.A., 2004, Invertebrate habitat use in relation to fetch and plant zonation in northern Lake Huron coastal wetlands, Aquat. Ecosyst. Health Manag. 7: 249-267.

Cai Y., Lu Y., Liu J., Dai X., Xu H., Lu Y., Gong Z., 2016, Macrozoobenthic community structure in a large shallow lake: Disentangling the effect of eutrophication and wind-wave disturbance, Limnologica 59: 1-9.

Cattaneo A., 1990, The effect of fetch on periphyton spatial variation, Hydrobiologia 206(1): 1-10.

Chambers P.A., 1987, Nearshore occurrence of submersed aquatic macrophytes in relation to wave action, Can. J. Fish. Aquat. Sci. 44(9): 1666-1669.

Cheng C.S., Lopes E., Fu C., Huang Z., 2014, Possible impacts of climate change on wind gusts under downscaled future climate conditions: Updated for Canada, J. Climate 27(3): 1255-1270.

Cheruvelil K.S., Soranno P.A., 2008, Relationships between lake macrophyte cover and lake and landscape features, Aquat. Bot. 88(3): 219-227.

Cooper M.J., Lamberti G.A., Uzarski D.G., 2014, Spatial and temporal trends in invertebrate communities of Great Lakes coastal wetlands, with emphasis on Saginaw Bay of Lake Huron, J. Great Lakes Res. 40: 168-182.

Cyr H., 1998, Effects of wave disturbance and substrate slope on sediment characteristics in the littoral zone of small lakes, Can. J. Fish. Aquat. Sci. 55(4): 967-976.

[EC] European Commission, 2000, Directive 2000/60/EC of the European Parliament and of the Council of 23 October 2000 establishing a framework for Community action in the field of water policy, Offic. J. Eur. Union L327 43: $1-72$.

Eichelberger S., McCaa J., Nijssen B., and Wood A., 2008, Climate change effects on wind speed, North American Windpower 7: 68-72.

Gabel F., Garcia X.F., Brauns M., Sukhodolov A., Leszinski M., Pusch M.T., 2008, Resistance to ship-induced waves of benthic invertebrates in various littoral habitats, Freshwater Biol. 53(8): 1567-1578.

James M.R., Weatherhead M., Stanger C., Graynoth E., 1998, Macroinvertebrate distribution in the littoral zone of Lake Coleridge, South Island, New Zealand-effects of habitat stability, wind exposure, and macrophytes, New Zeal. J. Mar. Fresh. 32(2): 287-305.
Jażdżewska I., Urbański J., 2013, GIS w nauce [GIS in Science], Acta Univ. Lodz. Fol. Geogr. Socio-Oecon. 14: 5-15.

Jones J.I., Murphy J.F., Collins A.L., Sear D.A., Naden P.S., Armitage P.D., 2012, The impact of fine sediment on macro-invertebrates, River Res. Appl. 28(8): 1055-1071.

Kajak Z., 2001. Hydrobiologia-limnologia: Ekosystemy wód śródlądowych [Hydrobiology-limnology: Inland water ecosystems]. Wyd. Naukowe PWN, Warszawa 360 pp. (in Polish).

Keddy P.A., 1982, Quantifying within-lake gradients of wave energy: interrelationships of wave energy, substrate particle size and shoreline plants in Axe Lake, Ontario, Aquat. Bot. 14: 41-58.

Koperski P., 2011, Diversity of freshwater macrobenthos and its use in biological assessment: a critical review of current applications, Environ. Rev. 19: 16-31.

Krodkiewska M., Michalik-Kucharz A., 2009, The bottom Oligochaeta communities in sand pits of different trophic status in Upper Silesia (Southern Poland), Aquat. Ecol. 43(2): 437-444.

Mardia K.V., Jupp P.E., 2000, Directional statistics, Wiley, Chichester 429 pp.

Margalef R., 1958, Information theory in ecology, Gen. Syst. 3: 36-71.

Mason L.A., Riseng C.M., Layman A.J., Jensen R., 2018, Effective fetch and relative exposure index maps for the Laurentian Great Lakes, Sci. Data 5: 180-295.

Pieczyńska E., 1990, Littoral habitats and communities, [in:] Jørgensen S.E., Löffler H. (eds), Guidelines of lake management. Vol. 3, Lake shore management, UNEP/ILEC, Kusatsu: 39-71.

Poikane S., Johnson R., Sandin L., Schartau A., Solimini A., Urbanic G., Arbačiauskas K., Aroviita J., Gabriels W., Miler O., Pusch M., Timm H., Böhmer J., 2016, Benthic macroinvertebrates in lake ecological assessment: A review of methods, intercalibration and practical recommendations, Sci. Total Environ. 543: 123-134.

Ratti C., Barton D.R., 2003, Decline in the diversity of benthic invertebrates in the wave-zone of eastern Lake Erie, 1974-2001, J. Great Lakes Res. 29(4): 608-615.

Rea T.E., Karapatakis D.J., Guy K.K., Pinder III J.E., Mackey Jr H.E., 1998, The relative effects of water depth, fetch and other physical factors on the development of macrophytes in a small southeastern US pond, Aquat. Bot. 61(4): 289-299.

Scheffer M., 2001, Ecology of shallow lakes, Kluwer Academic Publishers, Dordrecht, 357 pp.

StatSoft, Inc., 2014, STATISTICA: Data analysis software system (Version 12): www.statsoft.com.

Strayer D.L., Findlay S.E., 2010, Ecology of freshwater shore zones, Aquat. Sci. 72(2): 127-163.

ter Braak C.J.F., Šmilauer P., 2002, CANOCO Reference Manual and Cano Draw for Windows User's Guide. Software for Canonical Community Ordination (Version 4.5). Microcomputer Power: Ithaca: www.canoco.com. 
Tolonen K.T., Hämäläinen H., Holopainen I.J. Karjalainen J., 2001, Influences of habitat type and environmental variables on littoral macroinvertebrate communities in a large lake system, Arch. Hydrobiol. 152: 39-67.

Urbański J., Kryla-Straszewska L., 2010, Monitoring i modelowanie jezior w systemach geoinformacyjnych (Monitoring and modeling of lakes in geoinformation systems), [in:] Zwoliński Z. (ed.) GIS - woda w środowisku [GIS
- Water in the environment], Bogucki Wydaw. Nauk., Poznań: 121-146 (in Polish).

Weatherhead M.A., James M.R., 2001, Distribution of macroinvertebrates in relation to physical and biological variables in the littoral zone of nine New Zealand lakes, Hydrobiologia, 462(1-3): 115-129. 